\title{
Archer, Boltanski e Lahire: partindo com a teoria social de Bourdieu
}

VANDENBERGHE, Frédéric; VÉRAN, Jean-François (Orgs.). Além do habitus: teoria social pós-bourdieusiana. Rio de Janeiro: 7Letras, 2016.

Vittorio da Gamma Talone*

$\mathbf{V}$ a segunda metade do século XX, Pierre Bourdieu despontou na área das ciências sociais como um de seus pensadores mais relevantes a partir de uma extensa obra. Suas pesquisas e conceitos em muito influenciaram uma gama de sociólogos (seja por assumirem a força de seus argumentos, seja pela contraposição às suas proposições), dentre os quais, os três autores-base - os pilares a sustentarem as discussões realizadas, como veremos - da presente obra resenhada.

Ao adentrar o livro, deparamo-nos logo com dois textos introdutórios justificando seu ponto de partida "pós-bourdieusiano". Os organizadores, Frédéric Vandenberghe e Jean-François Véran, em "Novas sociologias: um exercício de teoria comparativa" (Capítulo 1), destacam a hegemonia das ideias de Bourdieu na última década a formatar o campo da sociologia internacional explicitamente entre bourdieusianos e antibourdieusianos. Destes, alguns autores apresentariam as principais "linhas de fuga" a conduzirem aos caminhos possíveis para a realização de diferentes sociologias a partir de distintas contraposições à Bourdieu. Tais autores seriam Bernard Lahire, Margaret Archer e Luc Boltanski, cada qual ganhando, no presente livro, uma parte destinada a um texto de sua própria autoria acrescentado por comentários, críticas e desenvolvimentos subsequentes de Cláudio Marques Martins Nogueira (Lahire), Vandenberghe (Lahire e Archer), Alexandre Werneck (Boltanski), e Véran e Diogo Corrêa (Boltanski).

A intenção é reunir textos de autores formados ou influenciados por Bourdieu e que propõem perspectivas trazendo os atores de volta ao centro do palco, contribuindo "para o desenvolvimento de uma sociologia pós-bourdieusiana que não seja antibourdieusiana" (p.21). Archer, Boltanski e Lahire, em suas sociologias (Boltanski \& Thévenot, 1991; Lahire, 2002; Archer, 2003), considerariam o campo como espaço de descoberta empírica e de exploração teórica, possibilitando a

\footnotetext{
* Vittorio da Gamma Talone é doutorando pelo Programa de Pós-Graduação em Sociologia do Instituto de Estudos Sociais e Políticos da Universidade do Estado do Rio de Janeiro (lesp/ Uerj), Rio de Janeiro, Brasil. Mestre pelo Programa de Pós-Graduação em Sociologia e Antropologia da Universidade Federal do Rio de Janeiro (PPGSA/UFRJ). <vittorio.talone@ gmail.com>.
} 
invenção de novos conceitos a serem exemplificados na pesquisa. Seus focos microssociológicos conduzem a sociologias dispensando o habitus: os atores possuiriam reflexividade, disposições plurais - a variar com contextos - ou competências críticas qualificando-os como "indivíduos historicamente situados e atuando em contextos empíricos particulares" (p. 16).

No Capítulo 2, "Os pós-bourdieusianos: retrato de uma família disfuncional", Vandenberghe propõe como ponto de partida pensar conjuntamente tais autores profundamente influenciados pela sociologia crítica de Bourdieu, posteriormente procurando se desvencilhar desta. Pois a mesma seria vista como uma máquina de reprodução na medida em que a agência é ausente - "quase não haveria reflexidade no seu sistema" (p. 30). Em semelhança, Lahire, Archer e Boltanski dão ênfase aos atores - suas posições são pluralistas. Avancemos agora nos três pilares a sustentarem a presente obra.

A Parte I, destinada a Bernard Lahire, é denominada "A sociologia em escala individual", sendo iniciada pelo texto - de autoria do próprio autor - "O homem plural ou a sociologia em escala individual". Lahire destaca que pesquisadores frequentemente observam os atores atentando apenas para uma cena, ou seja, um só contexto, deduzindo deste as disposições, culturas, visões de mundo, como faria Bourdieu, "sem pensar no comportamento dos mesmos atores em outras circunstâncias ou contextos" (p. 39).

Para o autor, o interesse pela constituição social do indivíduo em escala individual forçaria ver heterogeneidade onde se poderia pressupor homogeneidade. Um ator vivenciaria no dia a dia uma pluralidade de contextos sociais não homogêneos e/ ou contraditórios, de forma a ser pensado como possuindo um estoque de disposições, de hábitos ou de capacidades "não homogêneo, não unificado e com práticas consequentemente heterogêneas (e mesmo contraditórias), que variam segundo o contexto social no qual ele se desenvolverá" (p. 43).

Para Lahire, então, os momentos de vida de um ser humano, onde se constituem seus diferentes hábitos e seus diferentes repertórios, não são todos equivalentes. Assim, o ator tem comportamentos que jamais seriam inteiramente previsíveis: "somos demasiado multissocializados e multideterminados para ser conscientes de nossos determinismos" (p. 45).

Em seguida, Nogueira comenta o raciocínio de Lahire em "Bernard Lahire: contribuições e limites de uma sociologia em escala individual". O autor destaca como esforço central do sociólogo francês a demonstração que a "realidade individual 
não pode ser deduzida diretamente das regularidades estabelecidas a partir de uma escala coletiva de análise" (p. 50), pois o social em escala individual apresentaria uma complexidade muito grande. Lahire chamaria nossa atenção para uma apreensão empiricamente mais detalhada da realidade individual.

Com isso, argumenta Nogueira, o trabalho de Lahire poderia ser entendido enquanto crítica e continuidade da obra de Bourdieu. Pois reconhece o habitus e as disposições, mas traz à nossa atenção uma heterogeneidade do passado individual incorporado em detrimento à ideia de habitus como originalmente em Bourdieu (2007): um sistema unificado e relativamente coerente de orientação das ações.

No entanto, há limites no pensamento destacado: faltaria ao projeto de Lahire uma teoria "mais consistente sobre o modo como os indivíduos lidam com seu contexto, seja no passado ou no presente, incorporando ou rejeitando, em maior ou menor grau e de maneira consciente ou não, diferentes influências sociais" (p. 51). Sem cuidado com esta questão, destaca Nogueira, o esforço de análise empírica da realidade individual realizado por Lahire correria o risco de produzir explicações ad hoc.

Avancemos agora à segunda parte do livro, intitulada "Realismo crítico e reflexividade", dedicada a colocar em discussão as ideias de Margaret Archer. Esta seção é iniciada como um capítulo da própria autora, "Explicação e compreensão podem ser ligadas numa história única?" Aqui, Archer busca realizar uma reflexão epistemológica sobre a possibilidade de se juntar explicação e compreensão, nos termos de Max Weber, em uma única perspectiva, buscando resolver o hiato entre estrutura e agência, estabelecendo uma mediação pela reflexividade.

Archer introduz um novo refinamento ao especificar justamente como explicação e compreensão podem, de fato, ser relacionadas a partir de sua abordagem morfogenética. A autora destaca que um sujeito possui o poder de refletir subjetivamente sobre as próprias circunstâncias e decidir o que fazer com elas ou a respeito delas. Lidar de fato com a subjetividade seria, então, abordar adequadamente a variação nas respostas dos agentes quando estão em uma mesma situação social. Teríamos de saber da deliberação interna dos agentes - a "subjetividade" destes.

Este seria o aspecto mais normalmente ignorado na sociologia e que Archer joga luz: a reflexividade por meio da qual deliberamos sobre nós mesmos em relação às nossas circunstâncias sociais. Assim, devemos atentar à conversação interna dos indivíduos, pois é ela que medeia a tomada de decisão ativando tanto os poderes estruturais quanto os culturais. 
Vandenberghe aproveita este momento da discussão para estabelecer relações e distâncias entre o proposto por Lahire e Archer com o capítulo "A sociologia na escala individual: Margaret Archer e Bernard Lahire" - fechando a Parte II. Para o autor, ambos os sociólogos estão desenvolvendo "um novo tipo de psicologia social" (p. 95), refletindo o interesse em compreender biografias individuais sociologicamente. A unidade de análise de ambos os autores seria a mesma: uma vida. Em suas diferenças, Archer enfatizaria o poder pessoal dos indivíduos (uma voluntarista), enquanto Lahire enfatiza o poder duradouro da socialização (um determinista).

Para verificar como os autores podem se conectar - o maior esforço de Vandenberghe corre neste sentido -, destaca que Archer e Lahire poderiam trabalhar conjuntamente em uma "sociologia reflexiva, contextual e disposicional na escala do indivíduo" (p. 112). Não opondo disposições a conversações, externo ao interno, objetivo ao subjetivo, Vandenberghe sugere situar tais elementos em um continuum e os investigar em situações concretas de ação, seja quando a consciência prática sobrepuja a consciência reflexiva ou também no sentido inverso. Com isso, conclui:

\begin{abstract}
Apenas quando situações concretas de ação forem levadas em conta poderemos fazer o que fez Archer pela teoria da estruturação: indicar quando as disposições têm precedência e a reflexividade é comparativamente fraca ou, ao contrário, quando as disposições estão fora de sincronia e a reflexividade é relativamente forte (p. 119).
\end{abstract}

Prossigamos agora com a terceira parte do livro, "Sociologia pragmática da justificação", focando na sociologia de Luc Boltanski primeiramente a partir de seu capítulo "Sociologia crítica ou sociologia da crítica" - tradução (e versão revisada) de um texto da primeira parte de um livro já conhecido de Boltanski (Boltanski \& Thévenot, 1991). O autor, juntamente a Laurent Thévenot, desenvolveu um quadro de análise - denominado Économies de la grandeur (EG) - que fornece um instrumento para analisar as operações que os atores lançam mão

quando, engajando-se na crítica, devem justificar as críticas que antecipam, mas também quando devem se justificar frente à crítica ou colaborar na busca de um acordo justificado (p. 129).

Ao tomar por objeto o trabalho crítico operado pelos próprios atores, renunciou-se à "intenção crítica da sociologia clássica" (p. 131-132), como presente em Bourdieu. As operações críticas realizadas pelos atores, ausentes na sociologia crítica, 
seriam um objeto essencial para a compreensão de nossas sociedades - sociedades críticas:

É assim que, no modelo [das EG], em que a antropologia faz da capacidade crítica o critério que permite distinguir as pessoas dos outros seres, nós fundamos a possibilidade da crítica sobre a existência de várias cités [mundos ideais cujos princípios tomaríamos de referência para agir na modernidade] que permitem o desengajamento da situação presente. É apoiando-se sobre um princípio de justiça de uma outra cité que podemos nos subtrair do modelo de justiça do qual dependem a situação na qual estamos engajados (p. 144-145).

Esta linha de pensamento implica o maior acúmulo possível de relatórios produzidos pelos próprios atores. Trata-se de atentar à competência cognitiva destes a pretenderem uma validade universal para sustentarem suas objetividades na crítica, tornando-a aceitável aos outros. Os sociólogos da crítica, portanto, renunciam a apresentar suas próprias versões da realidade com a intenção de ter a última palavra, apostando ontologicamente na capacidade moral e crítica dos atores.

Ao pensar a necessidade destacada por Boltanski (e Thévenot) de universalização de nossa postura/argumentação, na vida moderna, para essa ser tida como cabível por terceiros, Alexandre Werneck escreve o capítulo "A força das circunstâncias: sobre a metapragmática das situações". O autor destaca que, se as pessoas têm capacidade crítica e criticam as qualificações impostas em geral, é porque elas podem não aceitar a própria ideia de universal. O foco de Werneck é pensar as implicações da "impossibilidade do universal" (p. 159) no âmbito da moral: ela se permitiria espaço para o relativismo, ampliando as possibilidades de ação, potencializada pelas circunstâncias.

O ato de dar uma desculpa, por exemplo, justamente demonstraria a existência de uma circunstância, imprevista no plano de ação, dotada de uma característica absolutamente especial. Haveria, então, uma possibilidade para além das capacidades crítica e moral - afirmadas na sociologia da crítica -, uma capacidade para se voltar às próprias situações em que nos inserimos: é a capacidade metapragmática. Werneck evidencia uma moral que consegue ser ad hoc.

Assim, o autor desenvolve um modelo evidenciando a moral enquanto administração e direcionamento do bem (este como princípio substantivo de ação: o que se busca efetivar numa ação) nas mais diversas situações em que as pessoas podem se criticar - visando justamente esclarecer tal direcionamento -, propondo uma 
geometria distinta ao modelo das EG de Boltanski e Thévenot, pensando em "efetivação" (p. 177): aponta-se para o questionamento a respeito da concretização de situações para a geração de consequências. É a radicalização do pragmaticismo.

Ainda refletindo o modelo de Boltanski, no último texto do livro, "A 'justificação' como modelo político de regulação: reflexão a partir do contexto brasileiro", Corrêa e Véran estabelecem um diálogo entre a sociologia da justificação de Boltanski e Thévenot (1991) e o paradigma de DaMatta (1986) da "navegação social brasileira" - navegar seria uma capacidade das pessoas de se conduzirem no mundo, trafegando entre situações rotineiras e de disputa, modelando o comportamento ao registro situacional demandado.

Os autores indicam que o modelo de Boltanski e Thévenot permite deslocar a "matriz damattiana" de suas próprias armadilhas sem desfazer sua base: rompe com a identificação de DaMatta do que seriam traços pré-modernos da estrutura social brasileira. Seus conceitos seriam

a expressão ou realização prática de uma competência social humana geral, [...] a de saber relativizar e ponderar a obrigatoriedade formal da aplicação de uma norma ou regra impessoal (p. 200).

Por outro lado, com DaMatta, submete-se a justificação do modelo das EG à sua própria prova, pensando-a também como modelo político. O "jeitinho" evidenciaria uma possibilidade de acordos, dando-se menos em razão de sua relação com um valor geral a transcender o autointeresse das partes e mais relacionado com as necessidades pragmáticas e contingências da situação.

Assim, os autores deste capítulo buscam "uma densificação política e pragmática [de ambos] modelos destacados" (p. 194). O objetivo final é pensar quais seriam as implicações do modelo ao qual se chegou, construído como tipo ideal, atentando ao Brasil. Com isso, concluem:

A eficácia de um [tal] modelo de regulação política pela sociabilidade ordinária precisaria ainda - mais que nunca - [...] da regra da igualdade como condição prática de uma navegação social fluida (p. 210).

Ao analisar os principais pontos do livro, vemos esta obra figurar como relevante não só àqueles que desejam introduzir-se no debate de teorias pós-bourdieusianas - no sentido de desenvolvidas a partir de questionamentos a conceitos fundamentais de Bourdieu -, como representadas aqui pelas disposições plurais de 
Lahire, pelo realismo crítico de Archer e pela sociologia da crítica de Boltanski, mas também a pesquisadoras/es interessados em aprofundar-se nas mesmas, na medida em que se apresentam textos de autoria própria dos pilares destacados (originais ao menos em suas traduções ao português), organizados em diferentes partes do livro, ainda seguidos do esforço de pensamento em termos de aproximações, limites, e possibilidades abertas ou não exploradas destacados por Nogueira, Vandenberghe, Werneck, Corrêa e Véran.

\section{Referências}

ARCHER, Margaret. Structure, agency and internal conversations. Cambridge (UK): Cambridge University Press, 2003.

BOLTANSKI, Luc. L'amour et la justice comme compétences: trois essais de socilogie de l'action. Paris: Métaillé, 1990.

BOLTANSKI, LUC; THÉVENOT, Laurent. De la justification: les économies de la grandeur. Paris: Gallimard, 1991.

BOURDIEU, Pierre. A distinção: crítica social do julgamento. São Paulo; Porto Alegre: Edusp; Zouk, 2007 [1979].

DAMATTA, Roberto. O que faz o brasil, Brasil? Rio de Janeiro: Rocco, 1986.

LAHIRE, Bernard. Homem plural: os determinantes da ação. Petrópolism (RJ): Vozes, 2002 [2001]. 
